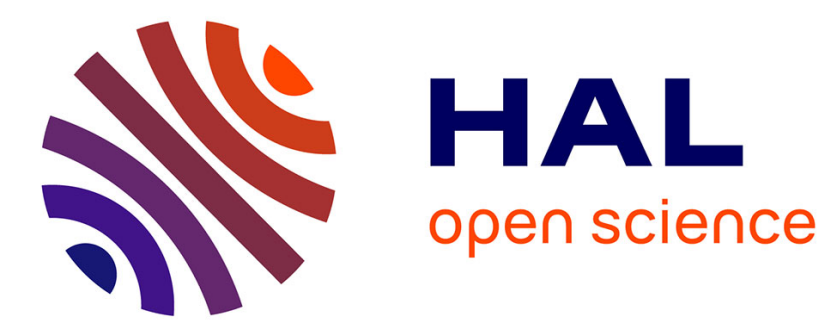

\title{
New insights into the formation of HIV-1 reverse transcription initiation complex.
}

Pierre Barraud, Cyril Gaudin, Frédéric Dardel, Carine Tisné

\section{To cite this version:}

Pierre Barraud, Cyril Gaudin, Frédéric Dardel, Carine Tisné. New insights into the formation of HIV-1 reverse transcription initiation complex.. Biochimie, 2007, 89 (10), pp.1204-10. 10.1016/j.biochi.2007.01.016 . hal-00218345

\section{HAL Id: hal-00218345 https://hal.science/hal-00218345}

Submitted on 27 Jan 2008

HAL is a multi-disciplinary open access archive for the deposit and dissemination of scientific research documents, whether they are published or not. The documents may come from teaching and research institutions in France or abroad, or from public or private research centers.
L'archive ouverte pluridisciplinaire HAL, est destinée au dépôt et à la diffusion de documents scientifiques de niveau recherche, publiés ou non, émanant des établissements d'enseignement et de recherche français ou étrangers, des laboratoires publics ou privés. 
New insights into the formation of HIV-1 reverse transcription initiation complex.

Pierre Barraud (1), Cyril Gaudin (2), Frédéric Dardel (1) and Carine Tisné (1)*.

(1) Laboratoire de Cristallographie et RMN biologiques, Université Paris Descartes, CNRS, 4 avenue de l'Observatoire, 75006 PARIS.

(2) Laboratoire de Chimie et de Biologie Structurale, ICSN, CNRS, 1 avenue de la Terrasse, 91198 Gif-sur-Yvette.

* Corresponding author:

Dr Carine Tisné

33153731572

fax: 33153739925

email: carine.tisne@univ-paris5.fr 


\section{ABSTRACT}

HIV-1 reverse transcriptase uses the host $\operatorname{tRNA}_{3}^{\text {Lys }}$ as a primer for the synthesis of the minus DNA strand. The first event in viral replication is thus the annealing of tRNA to the primer binding site (PBS) in the 5' UTR of the viral RNA. This event requires a major RNA rearrangement which is chaperoned by the viral NC protein. The binding of NC to nucleic acids is essentially non-specific, however, $\mathrm{NC}$ is known to bind selectively to hairpins located in the 5 ' region of the viral RNA. In a previous study, using an NMR approach in which the reaction is slowed down by controlling temperature, we were able to follow details in this RNA unfolding/refolding process and to uncover an intermediate state. We showed that annealing initiates at the junction between the acceptor and the $\mathrm{T} \Psi \mathrm{C}$ stems, and that, at physiological temperature, complete annealing is reached only in the presence of $\mathrm{NC}$, probably when the zinc fingers contact the T $\Psi C / D$ loops.

In the present work, we have refined our model of the formation of the $\mathrm{tRNA}_{3}^{\mathrm{Lys}} / \mathrm{PBS}$ duplex. First, we show that annealing can initiate both from the single-stranded CCA 3'-end bases of the acceptor stem and from the bases in the TYC stem. Secondly, by NMR and fluorescence spectroscopy, we have studied the complex between the NC protein and RNA hairpins that mimic the $\mathrm{D}$ and $\mathrm{T}$-arms of the $\mathrm{tRNA}_{3}^{\mathrm{Lys}}$. Interestingly, the NC protein shows strong and specific binding to the D-arm of $\mathrm{tRNA}_{3}^{\mathrm{Lys}}$, which could explain the overall annealing mechanism.

KEYWORDS : HIV, reverse transcription, $\mathrm{tRNA}_{3}^{\text {Lys }}$, nucleocapsid, NMR

ABBREVIATIONS : BME : 2-mercaptoethanol, HIV: Human Immunodeficiency Virus, HSQC: Heteronuclear Single Quantum Correlation, NC : nucleocapsid, PBS: Primer Binding Site, TROSY: Transverse Relaxation Optimized Spectroscopy. 


\section{INTRODUCTION}

In retroviruses, initiation of reverse transcription is primed by a cellular tRNA that is encapsidated in viral particles. $\mathrm{tRNA}_{3}^{\mathrm{Lys}}$ is the natural primer of all immunodeficiency viruses, including the type 1 human immunodeficiency virus (HIV-1) [1-3]. The HIV-1 nucleocapsid protein (NC) is a short, basic, nucleic-acid binding protein with two zinc finger domains, each containing the invariant $\mathrm{CCHC}$ metal-ion binding motif. The mature protein (55 amino acid residues) is produced by proteolytic cleavage of the Gag precursor and is found in the interior of the virus particle, where it is tightly associated with genomic RNA. $\mathrm{NC}$ or the NC domain in Gag is involved in multiple functions during the virus replication cycle, including genomic RNA packaging, primer placement on viral RNA, reverse transcription, and integration. Many of these functions rely on the nucleic acid chaperone activity of $\mathrm{NC}$, i.e. its ability to catalyse nucleic acid conformational rearrangements that lead to the most thermodynamically stable structure (for recent reviews [4-6]).

In a previous study [7], we were able to observe the progressive formation of the HIV-1 reverse transcription initiation complex using heteronuclear NMR of RNA-RNA-protein complexes under controlled temperature conditions. In particular, we have identified a nucleation site, at the end of the acceptor stem, where the viral RNA starts invading the tRNA $_{3}^{\text {Lys }}$ structure. In addition, we were also able to characterize the different roles of the nucleocapsid protein during the formation of the initiation complex. In our model, the viral NC protein plays a key role by "unlocking" stable 3D structure of the primer tRNA through specific interaction with the D/T $\Psi \mathrm{C}$ loops. Therefore, at the end of this study, the question of the involvement of the 3'-end unpaired CCA bases of $\mathrm{tRNA}_{3}^{\mathrm{Lys}}$ primer in the annealing process was still open. In addition, the mechanism of the specific 3D structure opening was still not clearly understood.

In the present report, we show that the annealing can proceed from two starting points in the $\mathrm{tRNA}_{3}^{\mathrm{Lys}}$ primer, one at the beginning of the acceptor stem and the second at the end of the $\mathrm{T}$ stem. Both sites can be used by the viral RNA to begin its annealing with the 18 complementary bases of $\mathrm{tRNA}_{3}^{\mathrm{Lys}}$ acceptor and T stems. The presence of NC protein is not 
necessary at this step, at least in vitro, but is essential to open the 3D structure of tRNA. The melting of the interaction at the level of the D/T $\Psi \mathrm{C}$ loops that locks the structure of the tRNA is possible through a specific interaction between the D loop and the NC protein. 


\section{MATERIALS AND METHODS}

\section{Samples}

The PBS (18 nucleotides) was ${ }^{15} \mathrm{~N}$-labelled on its guanine nucleotides by in vitro transcription from an oligonucleotide template containing a 2 '-O-methyl-G in position 2 (DNA template: 5'-G(2'OmeG)TCCCTGTTCGGGCGCCACTATAGTGAGTCGTATT-3') [8]. Labelled nucleotides were purchased from Spectra Gases Inc. The 20nt RNA obtained was then purified by electrophoresis. After electroelution and ethanol precipitation, the RNA was resuspended, micro-dialysed against a first buffer (10mM sodium phosphate, $\mathrm{pH} 6.4)$ and then against a second buffer ( $2 \mathrm{mM}$ sodium phosphate, $\mathrm{pH} 6.4)$ and freeze dryed. The NMR sample $(0.2 \mathrm{mM})$ was finally prepared by dissolving in $300 \mu \mathrm{L} \mathrm{H}_{2} \mathrm{O}$ containing $10 \%{ }^{2} \mathrm{H}_{2} \mathrm{O}$

The recombinant 55-residue NC protein (HIV-1 strain NL4-3) was overexpressed from the bacterial expression vector $\mathrm{pRD} 2$, which contains the NC coding region from HIV-1 strain NL4-3 subcloned into pET-3a (Novagen, WI). This plasmid was kindly given by M. F. Summers group [9, 10]. pRD2 was transformed into Escherichia coli strain BL21(DE3) pLysE and the overexpressed protein was purified as previously described $[9,10]$.

The small RNAs oligonucleotides (figure 2) were purchased from Dharmacon Research with 2'-o-bis (acetoxyethoxy)-methyl (ACE) protection. The samples were deprotected by following manufacturer recommendations and dialyzed several times against deionized water. The $\mathrm{pH}$ was adjusted between 6 and 6.5 before freeze-drying.

Human $\mathrm{tRNA}_{3}^{\text {Lys }}$ was expressed in vivo from a recombinant plasmid and purified as previously described [11].

\section{Fluorescence titrations}

Fluorescence measurements were performed at $30.0^{\circ} \mathrm{C}$ on a JASCO spectrofluorimeter. Excitation and emission wavelengths were $295 \mathrm{~nm}$ and $345 \mathrm{~nm}$ respectively. The excitation and emission bandwidths were $5 \mathrm{~nm}$.

Fluorescence titrations experiments were performed by adding increasing concentrations of nucleic acid to a fixed amount of NC protein $(1 \mu \mathrm{M})$ in buffers with different ionic strength 
(25 mM Na-acetate $\mathrm{pH}$ 6.5, $0.1 \mathrm{mM} \mathrm{BME,} 0.1 \mathrm{mM} \mathrm{ZnCl}_{2}$ for two salt concentrations, $25 \mathrm{mM}$ and $100 \mathrm{mM} \mathrm{NaCl}$, respectively). Fluorescence intensities were corrected for dilution and were fitted using equation (1) assuming that the $\mathrm{n}$ binding sites on the protein are totally independent and have the same dissociation constant $\mathrm{K}_{\mathrm{d}}$. Confidence limits on the $\mathrm{K}_{\mathrm{d}}$ were estimated by Monte-Carlo sampling using the MC-Fit program [12].

$$
I=I_{0}-\frac{I_{0}-I_{\infty}}{2 n N_{t}}\left(K_{d}+L_{t}+n N_{t}-\sqrt{\left(K_{d}+L_{t}+n N_{t}\right)^{2}-4 L_{t} n N_{t}}\right)
$$

where $\mathrm{I}_{0}$ : Fluorescence intensity without RNA, I: fluorescence intensity at a given concentration of RNA, $\mathrm{I}_{\infty}$ : fluorescence intensity at the plateau, $\mathrm{n}$ : number of RNA binding sites on the protein, $\mathrm{L}_{\mathrm{t}}$ : total concentration of RNA, $\mathrm{N}_{\mathrm{t}}$ : total concentration of protein.

\section{NMR Spectroscopy}

NMR data were recorded on a Bruker Avance DRX600 spectrometer equipped with a standard triple resonance probe and z-axis gradients, processed with NMRPipe/NMRDraw [13] and analyzed with SPARKY (T. D. Goddard and D. G. Kneller, SPARKY 3, University of California, San Francisco).

The formation of the $\mathrm{tRNA}_{3}^{\mathrm{Lys}} / \mathrm{PBS}$ duplex was followed in a ${ }^{1} \mathrm{H}_{-}{ }^{15} \mathrm{~N}$ TROSY experiment [14] carried out with $256 \mathrm{t} 1$ increments and $1024 \mathrm{t} 2$ data points. The spectral widths were $4194 \mathrm{~Hz}$ and $700 \mathrm{~Hz}$ in the proton and the nitrogen dimensions, respectively. Assignments of imino groups of the tRNA ${ }_{3}^{\text {Lys }}$ /PBS duplex were previously performed [7].

Footprint experiments of small RNAs on the uniformly ${ }^{15} \mathrm{~N}$-labeled $\mathrm{NC}$ protein were performed using echo-anti echo HSQC experiments [15] at $30^{\circ} \mathrm{C}$, at a concentration of 0.5 $\mathrm{mM}$ of each species in NMR buffer $(25 \mathrm{mM} \mathrm{Na}$-d3-acetate $\mathrm{pH} 6.5,25 \mathrm{mM} \mathrm{NaCl}, 0.1 \mathrm{mM}$ BME, $0.1 \mathrm{mM} \mathrm{ZnCl}$, $10 \%{ }^{2} \mathrm{H}_{2} \mathrm{O}$ ). Each partner was prepared at a concentration of about 2 $\mathrm{mM}$ in NMR buffer, and the required volumes of each sample were mixed together, immediately vortexed and incubated at $30{ }^{\circ} \mathrm{C}$ for $30 \mathrm{~min}$ before NMR data acquisition. Assignment of NC amide cross-peaks was determined using standard ${ }^{15} \mathrm{~N}$-based strategy. 


\section{RESULTS AND DISCUSSION}

- Where are the nucleation sites for tRNALys3/PBS duplex formation?

In a previous study [7], we showed that the melting process starts at the junction between the acceptor and T stems, at the level of weak AU and GU base pairs which can be easily disrupted and hence allow subsequent invasion of the tRNA ${ }_{3}^{\text {Lys }}$ structure by the viral RNA. However, our experimental approach, which relied on the NMR observation of imino protons, did not allow observation of PBS binding to the unpaired 3'-end of the tRNA, since the imino protons of the three first base pairs are carried by the viral RNA and only $\operatorname{tRNA}_{3}^{\text {Lys }}$ was ${ }^{15} \mathrm{~N}$ labelled. To further describe the very first event in the tRNA ${ }_{3}^{\text {Lys }} / \mathrm{PBS}$ annealing, we have thus performed the reciprocal experiment where, this time, the PBS is ${ }^{15} \mathrm{~N}$-labelled and the tRNA is unlabelled. The annealing process is then followed by monitoring the imino groups of the PBS (Figure 1) for which the assignment of proton NMR signals was already performed [7]. Figure $1 \mathrm{~b}$ shows the first base pairs that are stable enough to be observed in TROSY experiment, namely G183 and G194. The imino group signals of the free PBS are still mostly present, and only a small part of the PBS has begun to anneal to tRNA ${ }_{3}^{\text {Lys }}$. In addition, after 2 hours at $25^{\circ} \mathrm{C}$, in one dimensional ${ }^{1} \mathrm{H}$ spectrum where we can further observe non-labelled signals and more labile protons, the signals of U64, U66, G180, G192 and G193 in the duplex can be observed (Figure 2b) and are rather broad, explaining that G192 and G193 are not yet observed in the TROSY spectrum (Figure 1b). In addition, in NOESY experiment carried out at $25^{\circ} \mathrm{C}$, the NOE connections between U64 and G192, and between G192 and G193 are unambiguously observed (data not shown). After heating to $70^{\circ} \mathrm{C}$ and cooling back to $15^{\circ} \mathrm{C}$ (Figure 1c), all guanine signals corresponding to the duplex are present in TROSY experiment and their chemical shifts are identical to those previously assigned through a NOESY / TROSY strategy [7].

This shows that two distinct parts of $\mathrm{tRNA}_{3}^{\text {Lys }}$ are used by the viral RNA to grip its reverse transcription primer: G183 and G194 respectively contact C72 and C61 on tRNA ${ }_{3}^{\text {Lys }}$, at either end of the acceptor stem. This result reconciles apparently conflicting data, ours [6] and those of Hargittai et al. [16], which suggested two different initiation sites for annealing, 
either the centre of the cloverleaf structure or the 3 'end unpaired bases of the primer tRNA. Our current data indicates that apparently both sites are being used for annealing. It remains to be established whether the same viral RNA molecule can simultaneously invade the tRNA acceptor stem from both ends or whether some initiate at center of the tRNA while others “zip-in" from the 3'-end, in a statistical manner. Interestingly, within the tRNA ${ }_{3}^{\text {Lys }}$ tertiary structure [17], C72 and C61 are distant from each other by eleven nucleotides, i.e. exactly one A-helix turn apart and are thus located on the same side of the tRNA acceptor-T $\Psi C$ helix, i.e. in a favourable orientation for simultaneous invasion.

- NC protein binds specifically to the D-arm of tRNALys3.

We have previously shown that the presence of NC protein is necessary to promote the complete melting of the $T \Psi C / D$ loop-loop interaction that is required to obtain a full annealing [7] of $\mathrm{tRNA}_{3}^{\mathrm{Lys}}$ on the PBS. Indeed, the NMR signals of the T54 and $\Psi 55 \mathrm{~N} 3 \mathrm{H}$ that make hydrogen bonds with A58 base and phosphate, respectively, are conserved until the later stages of the annealing process. Heating to $80^{\circ} \mathrm{C}$ in the absence of $\mathrm{NC}$ or NC-mediated annealing at $37^{\circ} \mathrm{C}$ is required to destroy these interactions. This activity is nucleocapsidspecific and cannot be reproduced using poly-L-lysine, suggesting that the zinc knuckles could play an important part in this essential step of the viral cycle. This also strongly suggested that there existed an NC-specific binding site in the TYC/D loop region of the primer tRNA ${ }_{3}^{\text {Lys }}$. To investigate this hypothesis, we have studied the interaction of the NC protein with RNA hairpins mimicking the $\mathrm{D}$ and the $\mathrm{T}$ arms (Figure 3) by NMR and fluorescence spectroscopy. Indeed, the multiplicity of $\mathrm{NC}$ binding sites on $\mathrm{tRNA}_{3}^{\mathrm{Lys}}$ rendered analyses using the full length molecule intractable, even when stringency was raised by increasing salt concentration (data not shown). This is a result of the binding dynamics, as we previously showed that the NC protein slides from one site to another [18]. Reducing the target RNA length prevents this process. Binding assays to the various RNA using the intrinsic fluorescence of NC tryptophan 37 are summarized in Table 1. As a reference, the same experiments were also carried out on the SL3 HIV-1 genomic packaging signal that 
makes specific interaction with NC [9]. As previously described for packaging domain loops of HIV-1 RNA [19-21], tightly bound RNA quenched nearly all the fluorescence of NC. The NMR and fluorescence analyses were initially performed at $25 \mathrm{mM} \mathrm{NaCl}$, i.e. conditions similar to those used by Summers and co-workers to resolve the NMR structure of the SL3/NC complex [9]. Ionic strength was then increased to investigate the binding specifity. TYC hairpin bound to NC, however, increasing salt concentration strongly destabilised this

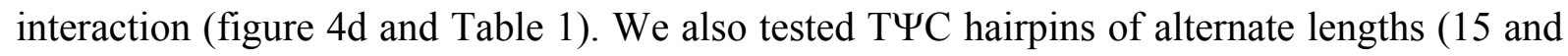
21 nucleotides) to investigate whether the number of NC binding sites or the stability of the T stem could play a role. The dissociation constant increased by a factor of two when the hairpin size was shortened from 21 nucleotides to 15 (Table 1). Longer stems thus improve the affinity and also increase the apparent number of NC binding sites. One can notice that the

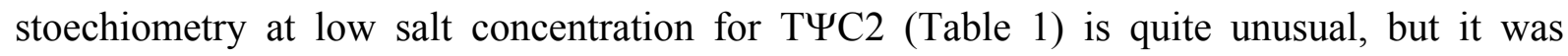
previously showed that non-specific interactions at low ionic strength between highly charged RNA molecule and NC can bias the number of binding site [21].

In contrast to what is observed with the $\mathrm{T} \Psi \mathrm{C}$ hairpins, $\mathrm{NC}$ binding to the $\mathrm{D}$ arm was tighter and much less sensitive to the salt concentration (Figure 4d). This behaviour is in line with what was observed for the specific binding of NC to the SL3 hairpin, for which a similar affinity and salt independence are seen (table 1). All these results show that the NC specifically binds to the $\mathrm{D}$ arm, whereas binding to the $\mathrm{T}$ arm is weaker and dominated by electrostatic effects, as evidenced by the salt dependence.

This different behaviour in $\mathrm{NC}$ binding of these two hairpins is observable in the corresponding NMR footprints on ${ }^{15} \mathrm{~N}$-labelled $\mathrm{NC}$, even at $25 \mathrm{mM} \mathrm{NaCl}$. At this ionic strength, the dissociation constant for the $\mathrm{NC}$ binding on $\mathrm{T}$ arm only differ from that on the $\mathrm{D}$ arm by a factor two. On the NMR spectra (Figure 4 a and c), only half of amide peaks are observed for the $\mathrm{T}$ footprint. This is typical of chemical exchange in the $\mu \mathrm{s}-\mathrm{ms}$ time scale, where NMR signals can disappear due to severe line broadening [22]. This is not surprising as it is known that the binding of $\mathrm{NC}$ on nucleic acids is very dynamic and $\mathrm{NC}$ is mobile on them especially when the binding is not specific. Contrary to the $\mathrm{T}$ arm, approximately 40 amide cross-peaks are still observed for the D arm. That means, chemical exchange reaches 
almost the slow exchange regime, which is caracteristic of tight binding. As previously described for the interaction with the packaging sequence $[9,23]$, the NC structure is significantly modified upon RNA binding and the NMR spectrum of the complex needs to be completely re-assigned. Taken together, these fluorescence and NMR observations indicate

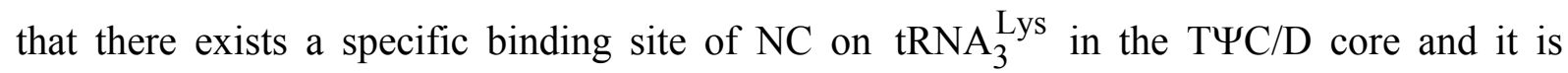
located in the D hairpin.

Based on both fluorescence and NMR structural studies performed to date [9, 19-21, 23], it appears that the CCHC-type zinc knuckle domains of NC contain specifically positioned hydrophobic residues that form an ideal binding surface for exposed $\mathrm{G}$ residues within nucleic acid sequences. More accurately, stacking interactions between Phe16 in the N-terminal finger and Trp37 in the C-terminal zinc finger and nucleic acid bases have been detected by fluorescence spectroscopy and have been proposed to be a major driving force for NC-nucleic acid interactions $[19,24]$. Indeed, NMR structures of SL2/NC and SL3/NC complexes [9, 23] show close interactions between Phe16 and Trp37 and guanine residues in single-stranded regions of SL2 and SL3 RNAs. In addition to the preferential binding of NC's zinc fingers to the single-stranded hairpin loop regions, the cationic N-terminal domain of NC binds to the double-stranded stem of the hairpin. From these data, the NC's zinc fingers are likely to interact with the guanine residues in the D loop whereas the $\mathrm{N}$-terminal residues would interact with the D stem. The D loop contains three guanine nucleotides (G15, G18 and G19) whereas the T loop contains only one (Figure 3). G15 makes a base pair with C48 and is rather buried within the 3D structure of RRNA $_{3}^{\text {Lys }}$ [17]. G19 makes a rather weak base-pair with C56, as two alternate conformations are observed in the crystal structure and, as a consequence of this mobility, could be readily accessible to interactions with NC. G18 makes a hydrogen bond with $\Psi 55$ (O6) and interestingly, the presence of $\mathrm{NC}$ in the annealing process is required to induce disappearance of the $\Psi 55(\mathrm{~N} 3 \mathrm{H})$ signal. Moreover, bases 16, 17 and 20 that surround G18 and G19 are completely exposed to the solvent that render nucleotide in the D-loop easily accessible. Therefore, within the D loop, G18 and G19 appear as likely candidates as being part of the specific NC binding site. Moreover, in the context of the annealing process between the PBS and the primer tRNA ${ }_{3}^{\text {Lys }}$, it makes more sense to bind 
to the D-loop rather than the TYC-loop, where the annealing to the PBS is taking place. 


\section{CONCLUSION}

In this paper, the use of selective labelling of the primer binding site allowed us to characterize the nucleation points of the annealing process between the PBS and the $\operatorname{tRNA}_{3}^{\text {Lys }}$. Moreover, we used small hairpins to mimic the $\mathrm{D}$ and $\mathrm{T}$ arms of $\mathrm{tRNA}_{3}^{\mathrm{Lys}}$ to determine the specific role of $\mathrm{NC}$ in the formation of $\mathrm{tRNA}_{3}^{\mathrm{Lys}} / \mathrm{PBS}$ duplex recognized by the HIV reverse transcriptase. Studying separate hairpins cannot obviously mimic the entire tRNA, in particular at the level of the TUC/D loops interaction. However, in the annealing

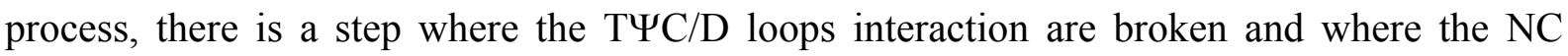
protein plays a crucial role. By stabilising this open state, $\mathrm{NC}$ will pull the equilibrium toward the "open state". In this context, the study of separate hairpins makes perfect sense, since they are likely to be an intermediate state in the unfolding pathway. We previously demonstrated that unless $\mathrm{NC}$ is added to the primer-PBS mixture, complete melting of $\mathrm{tRNA}_{3}^{\mathrm{Lys}}$ cannot be obtained. The specific interaction between NC and the D-loop that we observed here could be the key factor driving the unfolding process, thereby allowing complete annealing of tRNA $_{3}^{\text {Lys }}$ to the PBS. The NMR structure determination of the NC protein/D hairpin complex is under investigation and should provide useful information on the NC-mediated annealing process of $\mathrm{tRNA}_{3}^{\mathrm{Lys}}$ and on the design of anti-NC or anti-annealing drugs.

ACKNOWLEDGEMENTS: P. Barraud is supported by a studenship from Ministère de la Recherche. This work was supported by the French AIDS national Agency (ANRS) and 'Ensemble contre le SIDA' (Sidaction). 


\section{REFERENCES}

[1] S. Wain-Hobson, P. Sonigo, O. Danos, S. Cole, M. Alizon. Nucleotide sequence of the AIDS virus, LAV, Cell 40 (1985) 9-17.

[2] L. Kleiman, S. Caudry, F. Boulerice, M. A. Wainberg, M. A. Parniak. Incorporation of tRNA into normal and mutant HIV-1, Biochem Biophys Res Commun 174 (1991) 1272-1280.

[3] R. Marquet, C. Isel, C. Ehresmann, B. Ehresmann. tRNAs as primer of reverse transcriptase., Biochimie 77 (1995) 113-124.

[4] L. Kleiman, R. Halwani, H. Javanbakht. The selective packaging and annealing of primer tRNALys3 in HIV-1, Curr HIV Res 2 (2004) 163-175.

[5] J. G. Levin, J. Guo, I. Rouzina, K. Musier-Forsyth. Nucleic acid chaperone activity of HIV-1 nucleocapsid protein: critical role in reverse transcription and molecular mechanism, Prog Nucleic Acid Res Mol Biol 80 (2005) 217-286.

[6] C. Tisné. Structural bases of the annealing of primer tRNA(3Lys) to the HIV-1 viral RNA, Curr HIV Res 3 (2005) 147-156.

[7] C. Tisné, B. P. Roques, F. Dardel. The annealing mechanism of HIV-1 reverse transcription primer onto the viral genome, J Biol Chem 279 (2004) 3588-3595.

[8] C. Kao, M. Zheng, S. Rudisser. A simple and efficient method to reduce nontemplated nucleotide addition at the 3 terminus of RNAs transcribed by T7 RNA polymerase, Rna 5 (1999) 1268-1272.

[9] R. N. de Guzman, Z. R. Wu, C. C. Stalling, L. Pappalardo, P. N. Borer, M. F. Summers. Structure of the HIV-1 nucleocapsid protein bound to the SL3 psi-RNA recognition element., Science 279 (1998) 384-388.

[10] B. M. Lee, R. N. de Guzman, B. G. Turner, N. Tjandra, M. F. Summers. Dynamical behaviour of the HIV-1 nucleocapsid protein., J. Mol. Biol. 279 (1998) 633-649.

[11] C. Tisné, M. Rigourd, R. Marquet, C. Ehresmann, F. Dardel. NMR and biochemical characterisation of recombinant human tRNALys3 expressed in E. coli: Identification of post-transcriptional nucleotide modifications required for efficient initiation of HIV-1 reverse transcription., RNA 6 (2000) 1403-1412.

[12] F. Dardel. MC-Fit: using Monte-Carlo methods to get accurate confidence limits on enzyme parameters., Comput. Appl. Biosci. 10 (1994) 273-275.

[13] F. Delaglio, S. Grzesiek, G. W. Vuister, G. Zhu, J. Pfeifer, A. Bax. NMRPipe: a multidimensional spectral processing system based on UNIX pipes, J Biomol NMR 6 (1995) 277-293.

[14] J. Weigelt. Single scan, sensitivity- and gradient-enhanced TROSY for multidimensional NMR experiments., J. Am. Chem. Soc. 120 (1998) 10778-10779.

[15] J. Schleucher, M. Schwendinger, M. Sattler, P. Schmidt, O. Schedletzky, S. J. Glaser, O. W. Sorensen, C. Griesinger. A general enhancement scheme in heteronuclear multidimensional NMR employing pulsed field gradients, J Biomol NMR 4 (1994) 301-306.

[16] M. R. Hargittai, R. J. Gorelick, I. Rouzina, K. Musier-Forsyth. Mechanistic insights into the kinetics of HIV-1 nucleocapsid protein-facilitated tRNA annealing to the primer binding site, J Mol Biol 337 (2004) 951-968.

[17] P. Benas, G. Bec, G. Keith, R. Marquet, C. Ehresmann, B. Ehresmann, P. Dumas. The crystal structure of HIV reverse-transcription primer tRNA(Lys,3) shows a canonical anticodon loop, Rna 6 (2000) 1347-1355.

[18] C. Tisné, B. P. Roques, F. Dardel. Heteronuclear NMR studies of the interaction of tRNALys3 with HIV-1 nucleocapsid protein., J. Mol. Biol. 306 (2001) 443-454.

[19] C. Vuilleumier, E. Bombarda, N. Morellet, D. Gerard, B. P. Roques, Y. Mely. Nucleic acid sequence discrimination by the HIV-1 nucleocapsid protein NCp7: a fluorescence study, Biochemistry 38 (1999) 16816-16825.

[20] M. F. Shubsda, A. C. Paoletti, B. S. Hudson, P. N. Borer. Affinities of packaging domain loops in HIV-1 RNA for the nucleocapsid protein, Biochemistry 41 (2002) 5276-5282.

[21] A. C. Paoletti, M. F. Shubsda, B. S. Hudson, P. N. Borer. Affinities of the nucleocapsid protein for variants of SL3 RNA in HIV-1, Biochemistry 41 (2002) 15423-15428. 
[22] A. G. Palmer, 3rd, C. D. Kroenke, J. P. Loria. Nuclear magnetic resonance methods for quantifying microsecond-to-millisecond motions in biological macromolecules, Methods Enzymol 339 (2001) 204-238.

[23] G. K. Amarasinghe, R. N. De Guzman, R. B. Turner, K. J. Chancellor, Z. R. Wu, M. F. Summers. NMR structure of the HIV-1 nucleocapsid protein bound to stem-loop SL2 of the psi-RNA packaging signal. Implications for genome recognition, J Mol Biol 301 (2000) 491-511.

[24] Y. Mely, H. de Rocquigny, E. Piemont, H. Demene, N. Jullian, M. C. Fournie-Zaluski, B. Roques, D. Gerard. Influence of the $\mathrm{N}$ - and $\mathrm{C}$-terminal chains on the zinc-binding and conformational properties of the central zinc-finger structure of Moloney murine leukaemia virus nucleocapsid protein: a steady-state and time-resolved fluorescence study, Biochim Biophys Acta 1161 (1993) 6-18. 


\section{FIGURE LEGENDS}

Table 1: Binding Parameters of $\mathrm{NC}_{55}$ to $\mathrm{RNAs}$ stem-loop measured by fluorescence spectroscopy titration.

a: The dissociation constant $\mathrm{Kd}$ is indicated with the $96 \%$ confidence interval in parenthesis.

b: number of sites for $\mathrm{NC}_{55}$ on the RNA stem loop.

c: maximum extent of fluorescence quenching.

Figure 1: a) Secondary structure of the PBS (left), TROSY experiment of the ${ }^{15} \mathrm{~N}$-PBS alone

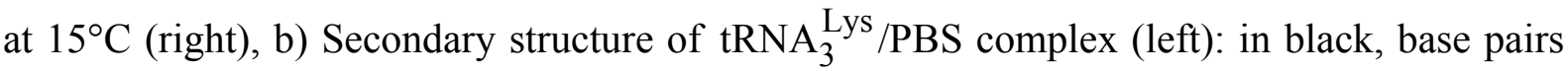
for which the imino groups is observed in TROSY experiment, in pink, base pairs for which

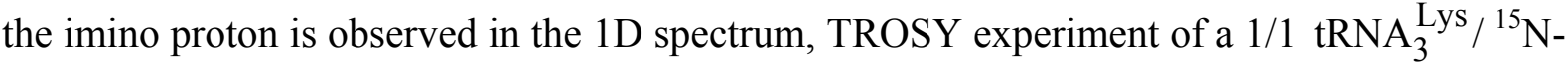
PBS at $15^{\circ} \mathrm{C}$ after heating the sample to $25^{\circ} \mathrm{C}$ (right). $\mathrm{Gx}$ cannot be assigned and probably belong to an intermediate structure. c) Secondary structure of tRNA ${ }_{3}^{\text {Lys }} / \mathrm{PBS}$ complex (left), TROSY experiment at $15^{\circ} \mathrm{C}$ after heating the sample to $70^{\circ} \mathrm{C}$ (right).

Figure 2: One dimensional proton NMR spectra at $15^{\circ} \mathrm{C}$ : a) just after the mixture between tRNA $_{3}^{\text {Lys }}$ and the PBS, b) after heating the sample for two hours at $25^{\circ} \mathrm{C}$ and cooling it back to $15^{\circ} \mathrm{C}$ to recorder the spectrum, c) after heating the sample to $70^{\circ} \mathrm{C}$ and cooling it back to $15^{\circ} \mathrm{C}$

Figure 3: Secondary structures of $\mathrm{tRNA}_{3}^{\mathrm{Lys}}$ and of hairpins that were designed to mimic tRNA $_{3}^{\text {Lys }} \mathrm{D}$ and $\mathrm{T}$ arms. The hairpins that mimic $\mathrm{tRNA}_{3}^{\mathrm{Lys}} \mathrm{T}$-arm carry the $\mathrm{T}$ and $\Psi$ base modifications whereas the D hairpin is not modified.

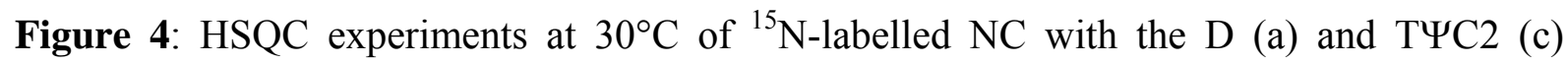
hairpins, in blue the reference spectrum and in red the spectrum of the equimolar 1/1 mixture. Fluorescence titrations of $\mathrm{NC}$ protein/D hairpin (b) and $\mathrm{NC}$ protein/T $\Psi \mathrm{C} 2$ hairpin (d) obtained by adding increasing concentrations of nucleic acid to a fixed amount of NC protein 
$(1 \mu \mathrm{M})$ in buffers with two ionic strength: $25 \mathrm{mM}$ and $100 \mathrm{mM} \mathrm{NaCl}$. 
